\title{
THE LIGHT-DEPENDENT BEHAVIOUR OF PLANULA LARVAE OF EUNICELLA SINGUL.ARIS AND CORALLIUM RUBRUM AND ITS IMPLICATION FOR OCTOCORALLIAN ECOLOGY
}

\author{
by \\ STEVEN WEINBERG \\ Institute of Taxonomic Zoology, University of Amsterdam, The Netherlands
}

\begin{abstract}
The behaviour of Mediterranean octocoral planulae was studied in light-dark situations and in a light gradient. Larvae of Eunicella singularts (Esper, 1794) reacted photopositively but it is uncertain which mechanism (klinotaxis or klinokinesis) determines this property. The blind larvae probably possess a dermal light sense, but it cannot be excluded that the yolk contains photosensitive carotenoids while the symbiotic zooxanthellae may also play a role. The photopositive behaviour of planulae of this species explains some aspects of the distributional ecology of adult colonies. It was also found that for the induction of settlement and metamorphosis the chemical properties of a given substratum seem to be far more important than its roughness. Larvae of Corallium rubrum (Linnaeus, 1758) are geonegative and indifferent to light. This latter fact is surprising, since in nature the colonies are exclusively found in dark places. It is supposed, therefore, that tolerance of the colonies rather than larval choice determines light-dependent zonation of this species in nature.
\end{abstract}

\section{RESUME}

Des expériences effectuées avec des larves planula d'Octocoralliaires méditerranéens ont permis d'étudier leur comportement dans des zones alternantes obscures et éclairées, ainsi que dans un gradient d'éclairement. Les larves d'Eunicella singularis (Esper, 1794) sont photopositives, sans que l'on puisse dire pour l'instant si c'est par klinocinèse ou klinotaxie. Ces larves ne possèdent pas d'yeux, mais ont probablement une sensibilité dermatoptique; il n'est pas exclu que des caroténoides photosensibles puissent être présents dans le vitellus, tandis que les zooxanthelles symbiotiques pourraient également jouer un rôle. Le comportement larvaire induit par cette photosensibilité permet d'expliquer certains aspects de la distribution écologique des colonies adultes. Par ailleurs, il apparait que les propriétés chimiques d'un substrat sont beaucoup plus importantes que sa rugosité pour l'induction de la fixation et de la métamorphose des larves. Les larves de Corallium rubrum (Linnaeus, 1758) sont géonégatives et apparemment indifférentes au facteur lumière; ceci est surprenant étant donné le caractère sciaphile des colonies. C'est pourquoi on avance l'hypothèse selon laquelle la distribution de cette espèce par rapport à la lumière dépendrait plutôt de la tolérance des adultes que de la sélection au stade larvaire.

\section{INTRODUCTION}

Marine benthic invertebrates, particularly sessile ones, are subjected to fluctuations in their physical environment. Most of these organisms (80\% according to Thorson, 1964) have a pelagic larval phase. Thus, whereas the adult animal has no means of escaping unfavourable environmental conditions, the larvae may actively seek a suitable place for settlement, or at least postpone settlement for several days to several weeks, thus increasing the chance that currents may carry them to a more appropriate spot. Many larvae show a distinct exploratory behaviour, before deciding whether or not a given place is suitable for settlement (KnightJones, 1951; Meadows \& Campbell, 1972; Thorson, 1950; Wilson, 1968). Among the triggering factors for settlement are light (Walton Smith, 1948; Thorson, 1964, Williams, 1965; Bayne, 1969; Crisp \& Ritz, 1973; Lewis, 1974; Wedler, 1975), roughness of substratum (Gohar, 1940; Crisp \& Ryland, 1960; Williams, 1975; Théodor, 1967), biological filming of substratum (KnightJones, 1951; Crisp \& Ryland, 1960; Lewis, 1974) and presence of conspecific individuals or biochemical influence of these, which may even lead to gregariousness (Knight-Jones, 1951; Thorson, 1964; Wilson, 1968; Bayne, 1969; Lewis, 1974; Williams, 1976). The generally accepted idea is that larvae settle at those places where the adults will encounter favourable living conditions.

In two recent papers, I have demonstrated that one of the primary parameters governing octocoral distribution in the Mediterranean is submarine daylight (Weinberg, 1978, 1979). This factor is so important in submarine ecology, that one author (Ercegovic, 1957) has proposed a general scheme for zonation based on this (universal) criterion.

Therefore it is important to know whether octocoral larvae are able to perceive and react to differences in irradiance. Very little is known about the behaviour of octocoral larvae (De LacazeDuthiers, 1864; Von Koch, 1887; Gohar, 1940; 
Théodor, 1967; Vighi, 1970; Weinberg \& Weinberg, 1979) but some studies on hexacoral larvae have shown the existence of three different tendencies:

(a) the larvae of some species swim towards light, sometimes becoming photonegative in their later phases. E.g.: Pocillopora damicornis cespitosa (Dana) (cf. Kawaguti, 1941; 1947), Favium fragum (Esper) (cf. Lewis, 1974), "all species with Zooxanthellae" (Kawaguti, 1944).

(b) the larvae of some species are indifferent to light, e.g. Seriatopora bystrix Dana (cf. Atoda, 1951b).

(c) The larvae of some species are photonegative, e.g. Galaxea aspera Quelch (cf. Atoda, 1951a).

Of the Mediterranean species studied (Weinberg, 1978, 1979) only two were known to yield planulae easily and abundantly, Eunicella singularis (Esper) (cf. Théodor, 1967; Weinberg \& Weinberg, 1979) and Corallium rubrum (Linnaeus) (cf. De Lacaze-Duthiers, 1864; Vighi, 1970). Because of the differences in distribution of these two species, I decided to attempt laboratory experiments with larvae of both of them, with the assumption that if light-dependent zonation is the result of larval choice, one might expect the larvae of $E$. singularis to be rather photopositive, those of $C$. rubrum photonegative.

\section{MATERIAL AND METHODS}

Colonies were collected by SCUBA-diving near Banyuls-sur-Mer (southern France). In the case of Eunicella singularis (Esper, 1794) it was possible to recognize ripe female colonies by scratching away part of the coenenchyme with a fingernail, thus revealing the 1-2 $\mathrm{mm}$ tall, pink eggs or planulae when present (see Weinberg \& Weinberg, 1979: plate 1, A). Only such colonies were collected and kept in aquaria with running seawater until planulation took place. This occurred in June and July. Although no record was kept, planulae seemed to be released in approximately equal amounts during the entire spawning period, showing no correlation with the lunar phases. In most hexacorals planulation takes place with peaks at certain lunar phases (Atoda, 1947, 1951a, b; Lewis, 1974).

In the case of Corallium rubrum (Linnaeus, 1758), the coenenchyme is too hard to be easily scratched away under water, and therefore colonies were collected at random, including male and female ones. These were also kept in aquaria with running seawater till planulation, in this case in the end of August and the first half of September. A massive release of larvae on September 1, 1978 suggests a possible correlation with New Moon, but observations over more years are needed to confirm this.

Larvae of both species are pyriform and ciliated. Those of $E$. singularis have an average length of $2.5 \mathrm{~mm}$, are pink and contain zooxanthellae (Théodor, 1967; Weinberg \& Weinberg, 1979), those of $C$. rubrum are about $1.5 \mathrm{~mm}$ long, snow-white and lack zooxanthellae (De Lacaze-Duthiers, 1864; personal observation). The larvae were collected by means of a suction flask (Weinberg \& Weinberg, 1979: fig. 1) for each experiment.

Directional reactions to light are quite common in invertebrates (Loeb \& Wasteneys, 1917; Ullyott, 1936a; Millott, 1957; Carthy, 1958; Fraenkel \& Gunn, 1961; Thorson, 1964; Williams, 1965; Stasko \& Sullivan, 1971) but the effects of nondirectional light gradients can be more easily correlated with zonation. The aim was therefore to carry out experiments in which the larvae could react only to differences in the intensity of the light and not to its direction. Experiments were carried out in a dark room, where the following experimental set-ups were used.

(a) Light-dark experiments took place by means of a mirror, mounted in an aluminium frame and facing downward under a $45^{\circ}$ angle (fig. 1). Upon this mirror a photographic slide was projected, consisting of a square subdivided into four quadrants, two diagonally opposite black ones, and two white ones. The only stimulus experienced by larvae swimming (or crawling) in the experimental plane was the change in light intensity, light coming from above in any case. The four-quadrant disposition was chosen to rule out the possible directional effect of some external disturbing factors, such as the working bench not being exactly level, a magnetic or electrical field, etc. Although in some experiments the slide was rotated over $90^{\circ}$, thus illuminating the previously black quadrants and vice versa, the numbering of the quadrants remained the same, i.e. in the experimental plane each quadrant kept its own number, whether illuminated or not. Two different types of experiment were carried out with this set-up. 


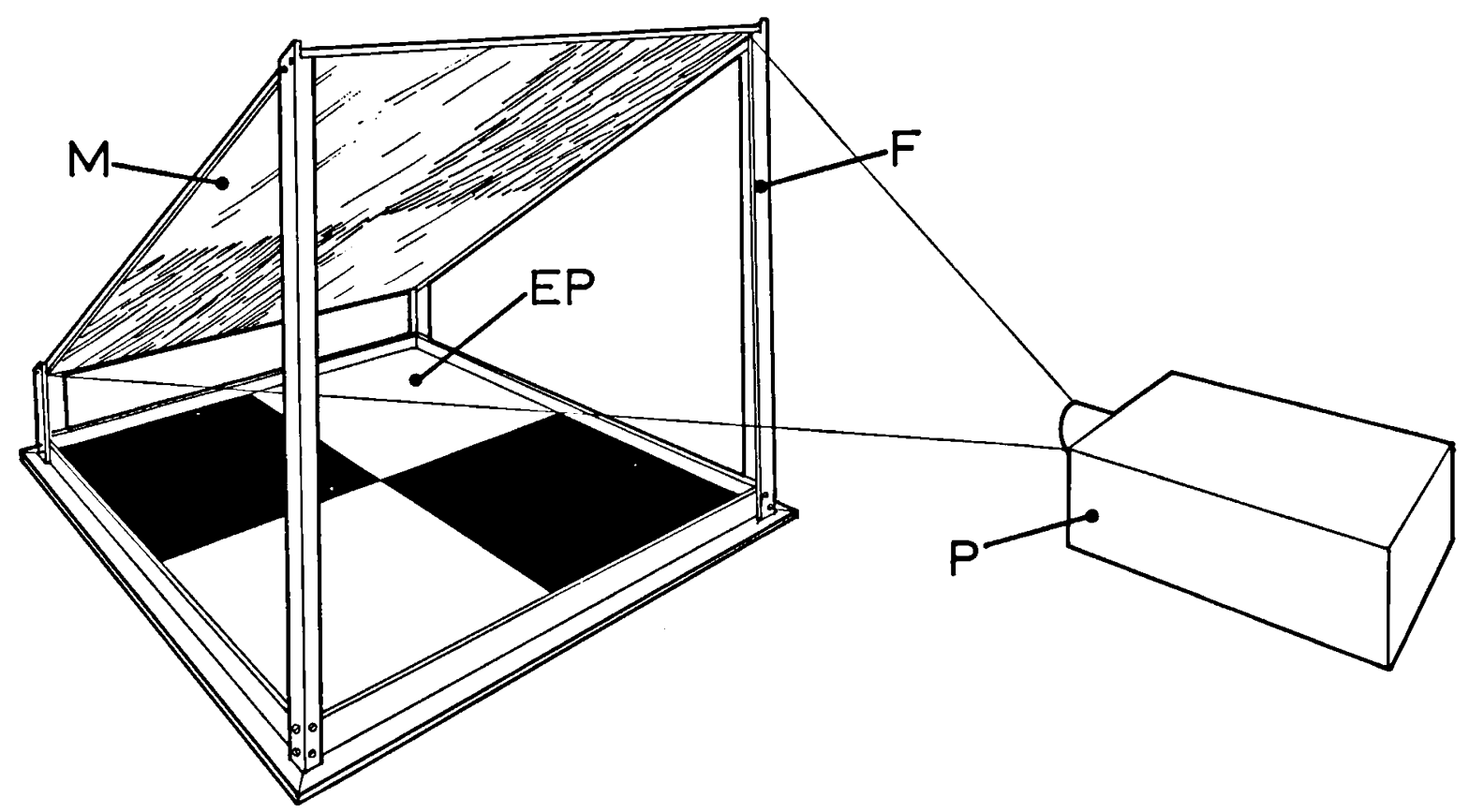

Fig. 1. Light-dark experiments. A photographic slide consisting of two dark and two light quadrants is projected by the projector (P) on the experimental plane (EP) via the $45^{\circ}$ mirror (M) mounted in an aluminium frame (F).

In the first one a circular glass dish $(\varnothing 19 \mathrm{~cm})$ was placed in the experimental plane so that its centre corresponded with the cross-lines separating the four quadrants. Larvae were released in the dish, and the seawater stirred to ensure a random distribution of the planulae. The numbers of planulae present in the dark sectors and in the light sectors were counted at different intervals. The glass dish was later replaced by a ring-shaped stoneware basin (inner $\varnothing 12 \mathrm{~cm}$, outer $\varnothing 26 \mathrm{~cm})$, the roughness of which was similar to that of natural substrata. After each experimentation series, the material was thoroughly washed, in order to remove possible traces left by the larvae. In control experiments, the experimental plane was either illuminated uniformly or kept entirely in the dark.

For the second type of experiment the entire experimental plane was occupied by a shallow square glass tray of $60 \times 60$ $\mathrm{cm}$, filled with seawater. Only a few larvae were released simultaneously and the swimming (crawling) pattern of one single planula observed at a time. By means of a grid system dividing the experimental plane in 256 small squares $(16 \times$ 16) and with the help of an electronic device clicking at s-second intervals, accurate tracking of the larvae was possible.

(b) Light gradient experiments were carried out in a larvodrome: a ring-shaped polyester basin (inner $\varnothing 40 \mathrm{~cm}$, outer $\varnothing 85 \mathrm{~cm}$ ). In order to release the larvae in an experimental set-up containing no other anisotropy than the (desired) light gradient, a ring-shaped basin was chosen, quite similar to the one used by Prodon (1976) for testing substratum preferences of insect larvae. The larvodrome (fig. 2) was made of darkgrey polyester and was subdivided into 16 equal sectors by means of white lines. The water was cooled by an immersed coolong spiral attached to a Colora TK4R cooler with a ther- mostat. Aeration was obtained by means of a pump and an airstone. Since both devices created a noticeable disturbance (temperature gradient and convection movement at the airstone) they had to be removed during the actual experiments. Prior to each experiment the water was cooled to about $15^{\circ} \mathrm{C}$ and well aerated. Cooling spiral and airstone were then removed from the larvodrome, the larvae were poured in and the water stirred in order to obtain thermal homogeneity and random distribution of the larvae. The basin was then covered by a gradient filter consisting of a transparent plexiglass cover subdivided into 16 sectors (corresponding to those of the basin). Each sector was coloured by blue transparent adhesive film so that from one side to the other two gradients of increasing shades of blue were obtained. The transmittance of segment 1 (colourless) was about 14 times higher than that of segment 9 (the darkest one). The central part of the gradient filter (corresponding to the dry central part of the basin) was painted black in order to avoid diffuse light disturbing the gradient. A Philips HPI/T $400 \mathrm{~W}$ high pressure mercury-iodine lamp with a lightflux of ca. $30000 \mathrm{~lm}$ was attached at about $70 \mathrm{~cm}$ above the basin. In this way the two light gradients obtained (one following the right half of the basin, one following the left half) ran from about $4.1 \mathrm{cal}$ $\mathrm{cm}^{-2}$ hour ${ }^{-1}\left(=47.6 \mathrm{~J} \mathrm{~m}^{-2} \mathrm{~s}^{-1}\right)$ in segment 1 to about $0.3 \mathrm{cal}$ $\mathrm{cm}^{-2}$ hour $\mathrm{r}^{-1}\left(=3.5 \mathrm{~J} \mathrm{~m}^{-2} \mathrm{~s}^{-1}\right)$ in segment 9. For Banyuls-surMer in the month of June and around noon this corresponds to values (for the visible spectrum $350-710 \mathrm{~nm}$ ) found in depths ranging from about $8 \mathrm{~m}$ to about $29 \mathrm{~m}$ (see Weinberg \& Cortel-Breeman, 1978). The number of larvae present in each sector was counted at irregular intervals. During each experiment, water temperature did increase gradually, but uniformly. In most experiments, the water did not reach temperatures of above $22^{\circ} \mathrm{C}$. Whenever it did, vitality of the 


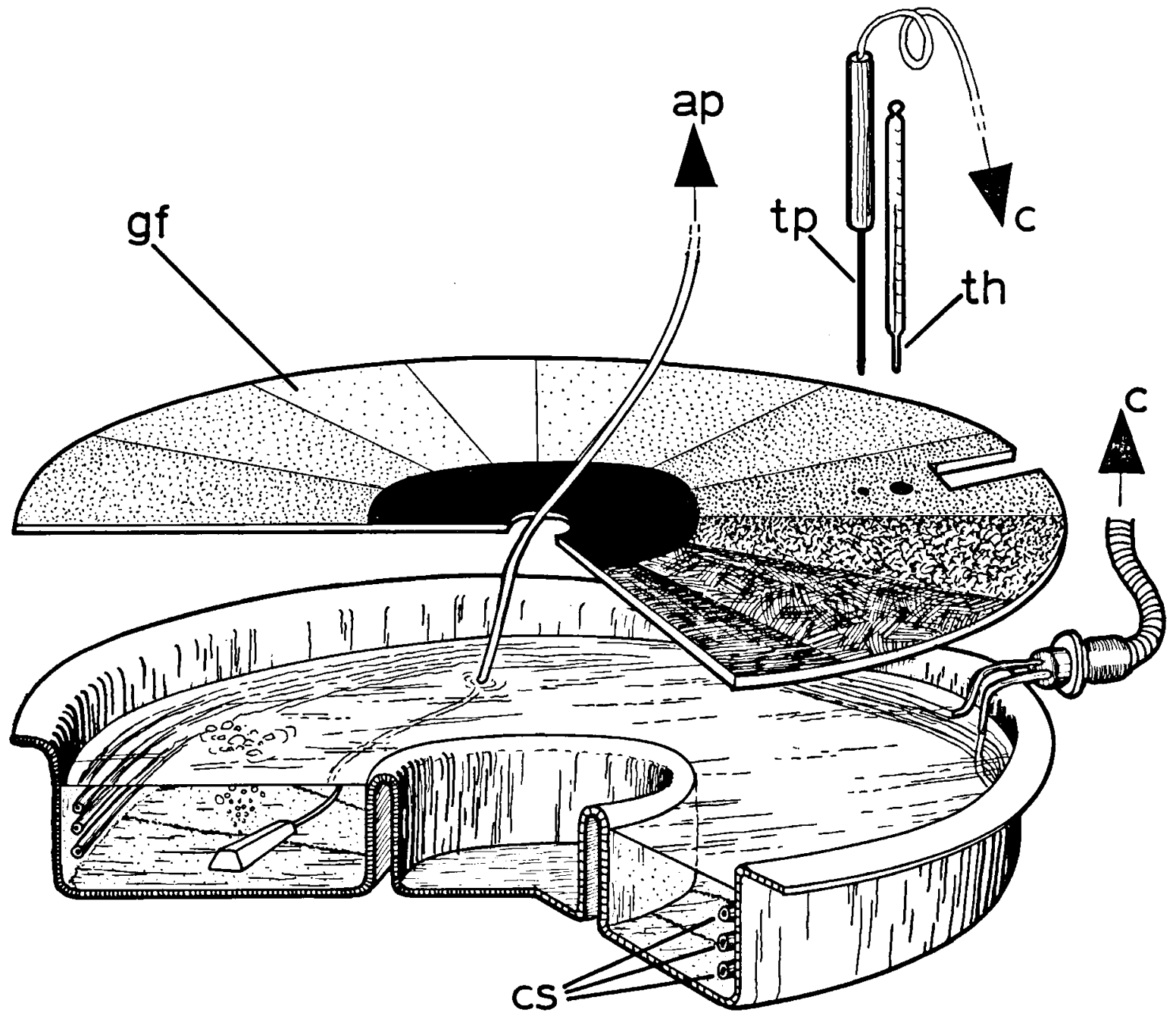

Fig. 2. Light gradient experiments. The larvodrome consists of a ring-shaped polyester basin (inner $\varnothing 40 \mathrm{~cm}$, outer $\varnothing 85$ $\mathrm{cm}$ ). The seawater is aerated by means of an airstone connected to an airpump (ap), and cooled with a cooling spiral (cs) connected to a cooler (c), which is regulated by means of a temperature probe (tp), while the temperature can be checked with the thermometer (th). A light gradient is obtained through a gradient filter (gf) covering the larvodrome.

larvae was checked. If they did not show any more signs of vigourous swimming, the experiment was stopped. After an experimental series, the larvodrome was thoroughly cleaned, and rotated over a random angle, in order to eliminate the influence of a possible preference of the larvae for a given spot in the basin.

\section{RESULTS}

\section{Eunicella singularis}

a. Light-dark experiments

Some typical results from light-dark experiments appear in fig. 3. To facilitate comparison the histograms represent percentages rather than absolute numbers of larvae, since the latter changed from one experiment to the other. The top row shows an experiment carried out on 15 June 1978 with about 450 larvae in the glass dish. The four-quadrant slide was projected in such a way that quadrants $1+3$ were dark and quadrants $2+4$ illuminated. Nearly six hours after stirring the larvae, $73 \%$ had moved to the illuminated sectors, while $27 \%$ were found in the dark ones. Without touching the dish or disturbing the larvae, the slide was now rotated over an angle of $90^{\circ}$ in the projector, causing the previously dark sectors to become illuminated and 

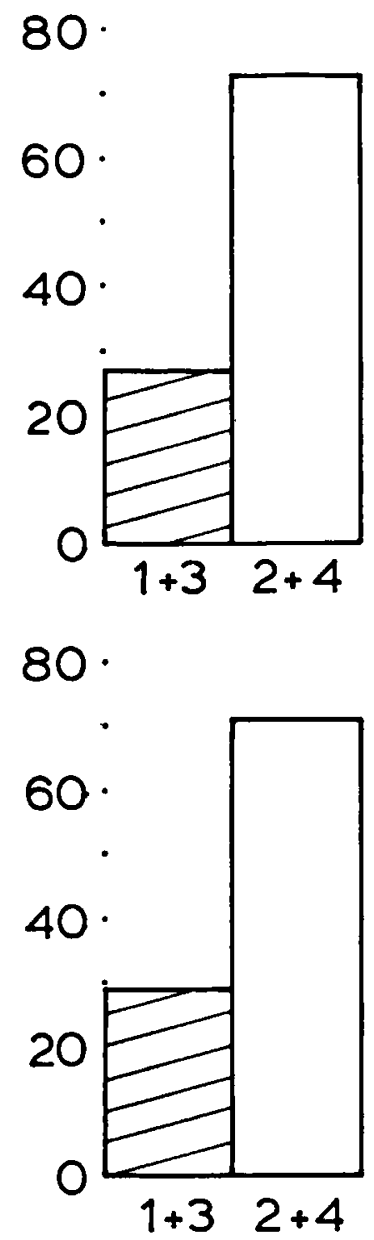

80 .
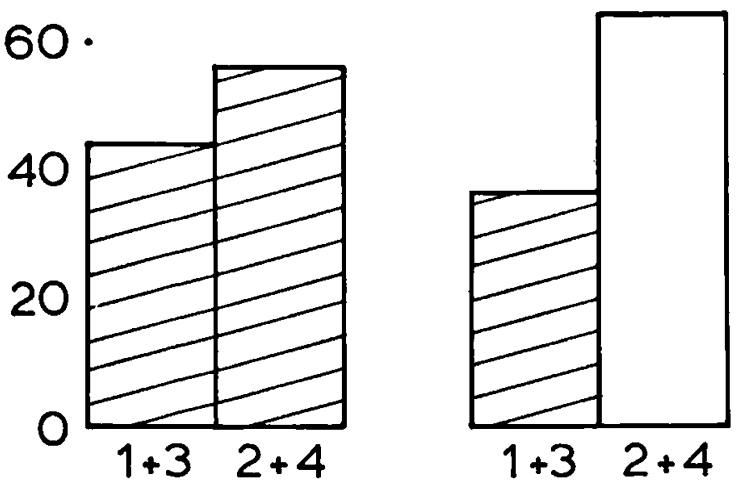

Fig. 3. Light-dark experiments with planulae of E. singularis. Histograms represent percentages of larvae found in quadrants $1+3$ and $2+4$ respectively. White areas indicate that the quadrants were illuminated, hatched areas that they were in the dark. Top row: after illuminating quadrants $2+4$ only, most larvae were found here (left histogram: after 5 hours vice versa. Eight hours after this change, the majority $(68 \%)$ of the larvae had again moved to the bright sectors. This experiment seems to prove that planulae of $E$. singularis seek illuminated places rather than dark ones, all other conditions being the same. Twenty-three such counts were carried out between 15 June and 21 July 1978, all with similar results. The significance of these results was tested with the non-parametric Mann-Whitney $U$-test (Elliott, 1977). $H_{o}$ (expectancy to find equal amounts of larvae in dark and illuminated sectors) could be rejected with an error probability of $0.1 \%(d=5.1, \mathrm{p} \ll 0.001)$.

Although inversion experiments such as the one described above tend to rule out the influence of any asymmetry inherent to the experimental set-up, I also undertook two types of control experiments. The first one appears in the middle row of fig. 3. The experiment was carried out with approximately 550 larvae on 10 July 1978 in the ring-shaped stoneware basin. First, sectors $2+4$ were illuminated for 9.5 hours, while sectors $1+3$ were left in the dark. This resulted in the familiar distribution of the left histogram. Then the slide was taken out of the projector, and the entire basin was now evenly illuminated. After 6 hours almost equal amounts of larvae were found in quadrants $1+3$ and $2+4$ (right histogram), indicating that when offered no alternative, the larvae will distribute themselves at random over the basin. Only two such experiments were carried out. In the other case the effect was not as pronounced as in the one just described ( $59 \%$ vs. $41 \%$ ). The number of experiments is too small for statistical analysis.

Another type of control experiment appears in the bottom row of fig. 3. This experiment, carried

and 50 minutes). After rotation of the slide over $90^{\circ}$ the larvae have moved to quadrants $1+3$, again the illuminated ones (right histogram: after 8 hours). Middle row: illumination of quadrants $2+4$ causes the majority of the larvae to move to these sectors (left histogram: after 9.5 hours). Removal of the slide (even illumination of all four quadrants) causes the larvae to redistribute themselves evenly (right histogram: after 6 hours). Bottom row: with all the quadrants in the dark, the larvae are distributed in almost equal amounts over the quadrants (left histogram: after 7 hours). Illumination of quadrants $2+4$ brings about a fast migration towards these sectors (right histogram: after 1 hour and 35 minutes). 
out on 15 July 1978 with about 350 larvae, started with the stoneware basin wrapped in aluminium foil, thus leaving the larvae completely in the dark. After 7 hours an almost equal distribution over sectors $1+3$ and $2+4$ was found ( $44 \%$ vs. $56 \%$ respectively). Illumination of quadrants $2+4$ brought back the familiar pattern after 1 hour and 35 minutes. This experiment also seems conclusive: without alternative the larvae will distribute themselves at random. When offered the choice between dark and bright sectors, they will opt for the latter. Since the results of four dark experiments were available, a Mann-Whitney $U$-test could be carried out. $H_{0}$ (equal amounts in quadrants $1+3$ and $2+4$ respectively) could not be rejected at the $5 \%$ level of significance, which tends to confirm the qualitative observations described above.

Settlement never occurred in experiments with the glass dish. In the stoneware basin with its coarse texture some cases of settlement and metamorphosis were observed, indicating that roughness plays a role, as was observed by Théodor (1967). However, in the holding aquaria, on natural substrata of comparable roughness (shells, rock, calcareous algae) the larvae settled much more readily. Extremely dense aggregations formed on the undersides of gorgonian holdfasts, with a roughness also comparable to the stoneware basin. This seems to indicate that chemical attraction (biological filming, conspecific substances) might be far more important than roughness of substratum in inducing settlement.

\section{b. Light gradient experiments}

These experiments were carried out in the larvodrome described in section II. The results of some typical experiments are shown in figs. 4-8. Each experiment consists of two simultaneous tests, since the set-up contains two (a left and a right) light gradients. In each figure, the left gradient is represented by open symbols, the right gradient by closed ones.

Fig. 4 shows the results of an experiment carried out on 27-28 June 1978. The experiment started in the evening, with about 1400 larvae distributed evenly in the basin without gradient filter. The room was left in the dark for over three hours. At the end of this period the larvae were distrib-
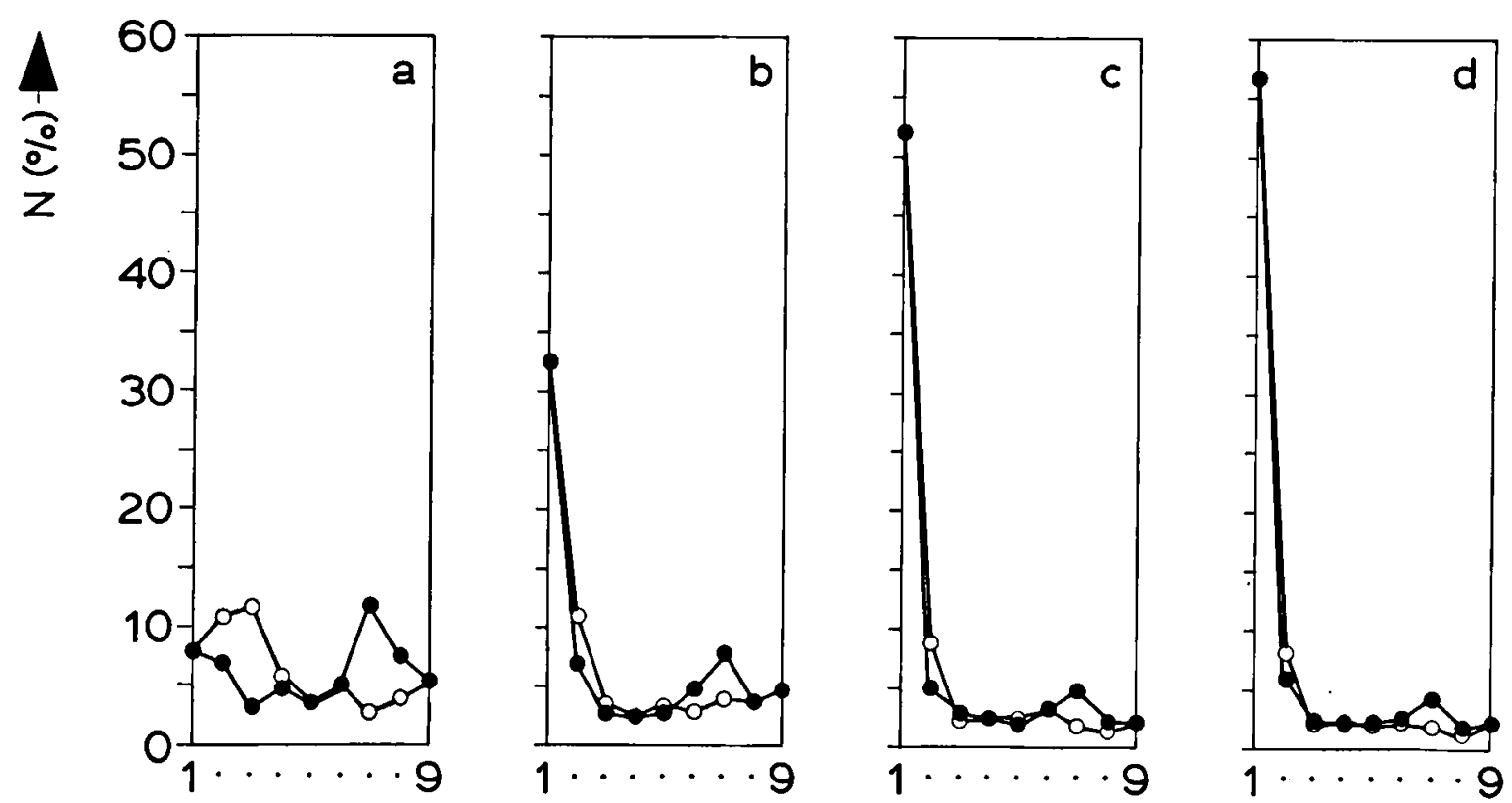

Fig. 4. Light gradient experiment in the larvodrome with larvae of E. singularis. Number of planulae (N in $\%)$ in sectors 1 to 9 . Open symbols $=$ left gradient, closed symbols $=$ right gradient. a, After 3 hours and 15 minutes in the dark, the larvae are distributed randomly over the sectors; $b$, after 3.5 hours in the gradient, the larvae start to move to sector 1 (the bright side of the gradient); c, ditto, after 8 hours and 45 minutes; d, ditto, after 13 hours and 15 minutes. Larvae move to the bright side. 
uted at random over the sectors (fig. 4a). At this point the gradient filter was placed over the basin, and the lamp switched on. After a period of 3.5 hours, it was observed that a large number of larvae had moved to the bright side of the gradient (fig. $4 \mathrm{~b}$ ), a tendency that increased over the following 10 hours (fig. 4c, d). This experiment again confirmed the idea that if offered the choice between light and dark, the larvae of $E$. singularis will opt for light conditions. Moreover, this experiment seemed to prove that the larvae were able to discern between extremely small differences in irradiance, since irradiance in sector 1 was only about $2 \%$ stronger than that in both sectors 2 .

Because it was not clear how fast the larval population responds to the gradient offered to them, another experiment was started on 30 June 1978, with about 1350 planulae, and during the first hours of the experiment more frequent observations were carried out. Fig. 5 shows the results. After one hour (fig. 5a) no apparent crowding at the bright side of the gradient was observed. The larval distribution was random and never departed very much from the $6 \%$ per sector one expects with even distribution. After two hours, however, larvae started to crowd at sector 1 (fig. 5b). This tendency increased during the following 9 hours (fig. 5c-f). After having exposed the larvae to the light gradient during 11 hours, the light was switched off for 36 hours. During this period, the larvae were left either in the dark, or in a very feeble gradient, due to weak illumination in the room. After this 36 hour period a situation quite similar to that in fig. $5 \mathrm{f}$ was found, and the lamp was switched on again. Eight and a half hours later a very strong crowding was recorded in sector 1 (fig. $5 \mathrm{~g}$ ).

The fact that the larvae did not redistribute themselves evenly during the 36 hour (nearly) dark period led to the suspicion that they simply preferred sector 1 over the other ones. On 18 July 1978 an experiment was therefore started with approximately 850 planulae. The disposition was similar to the one in the previously described experiments, except for the gradient filter, which had its bright side in sector 9 this time. After 20 hours, most of the larvae had gathered at this side (fig. 6a). The gradient filter was again rotated over $180^{\circ}$, and as a result the population switched sides in about 11 hours (fig. 6b). It was obvious now, as it was in the light-dark experiments, that the larval population shows a preference for strongly illuminated places, while preference for sector 1 was ruled out.

So far, the gradient experiment had yielded no other result than the light-dark experiments, except that the larvae are able to discern between very slight differences in irradiance. In the gradient, they always went to the brightest sector. What I had expected to find was a preference for an intermediate sector, corresponding to the zonation of the adults in nature, where highest population densities occur around $20 \mathrm{~m}$ depth (Weinberg, 1979). Because the larvae failed to show such a preference, it was suspected that the lamp was perhaps not strong enough to cause avoidance of the brightest sectors of the gradient. Therefore I decided to carry out one experiment outdoors. During a day with very clear sky (12 July 1978) the basin with 3300 larvae was put in full sunshine at 9 a.m. After 2.5 hours a net tendency to gather at the brightest side was again observed, although the left sector 2 contained more larvae than sector 1. On the other hand, the right sector 2 contained less (fig. 7a). This was due to the fact that the rays of the sun were falling obliquely through the uncoloured sector of the filter upon left sector 2 of the basin. Although the temperature had risen to an unnatural $25.9^{\circ} \mathrm{C}$, the planulae were still moving. Three hours later, the situation had hardly evolved (fig. $7 \mathrm{~b}$ ). The temperature was over $30^{\circ} \mathrm{C}$ now and all the larvae were dead. It was obvious, however, that even under these extreme circumstances, the planulae had moved to places with strongest irradiance.

That the larvae are able to perceive also extremely weak irradiances was discovered accidentally. In the night of 29-30 June 1978 a control experiment was undertaken. About 1350 larvae were put in the basin, which was left without gradient filter in the dark room. After 2.5 hours, distribution of the larvae was random, as expected (fig. 8a). The same was the case after 4 hours, although a slight, not very significant, migration seemed to have taken place towards sector 1 (fig. $8 b)$. Very early next morning, after 8.5 hours in 

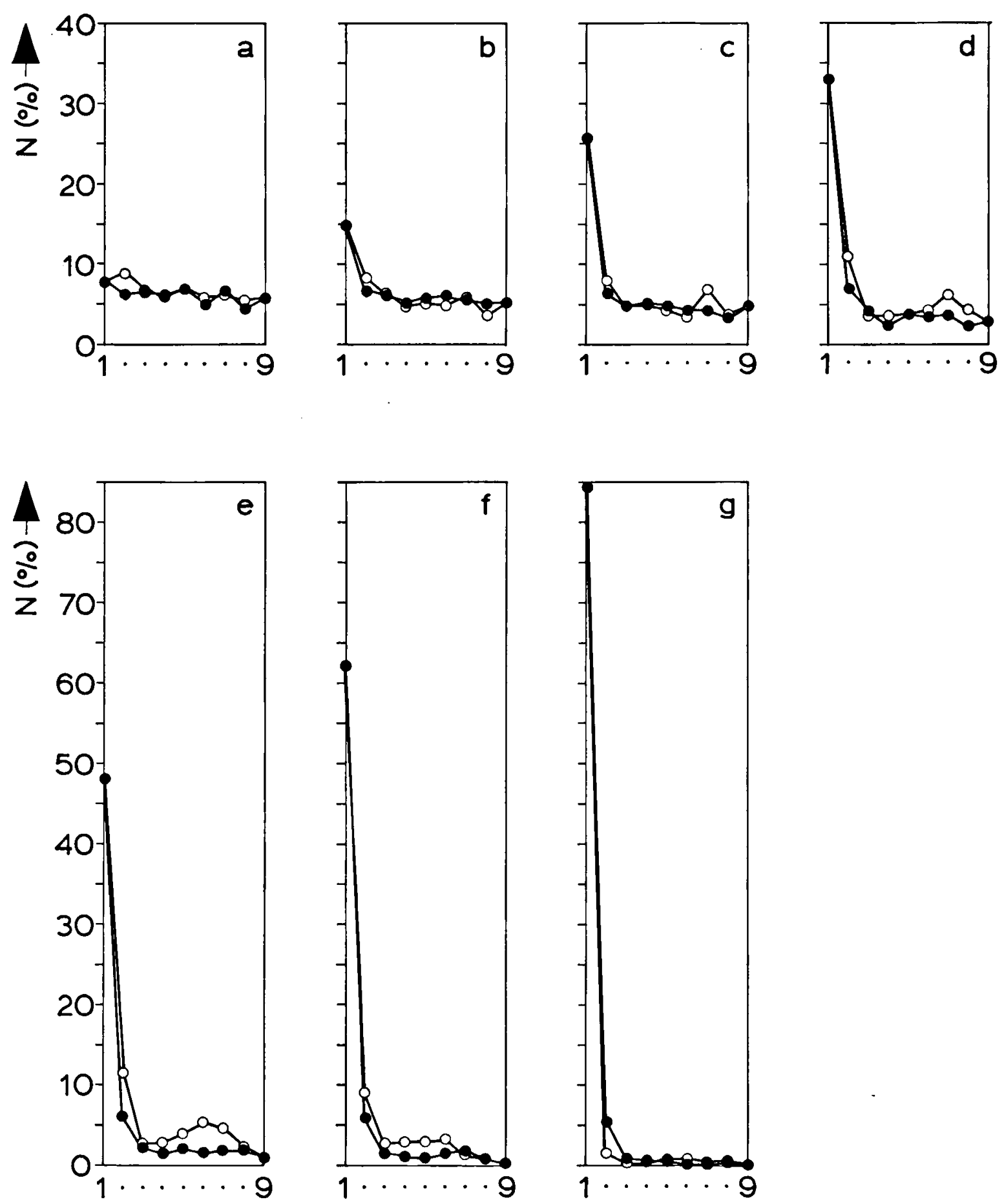

Fig. 5. As fig. 4. Bright side of the gradient in sector 1. a, After 1 hour; b, after 2 hours; c, after 3 hours; d, after 6 hours; e, after 9 hours; f, after 11 hours; $g$, after 11 hours light, 36 hours darkness and again 8.5 hours light. Two hours after the start of the experiment, the population has already partially moved to the bright side, and continues to do so during at least 48 hours. 

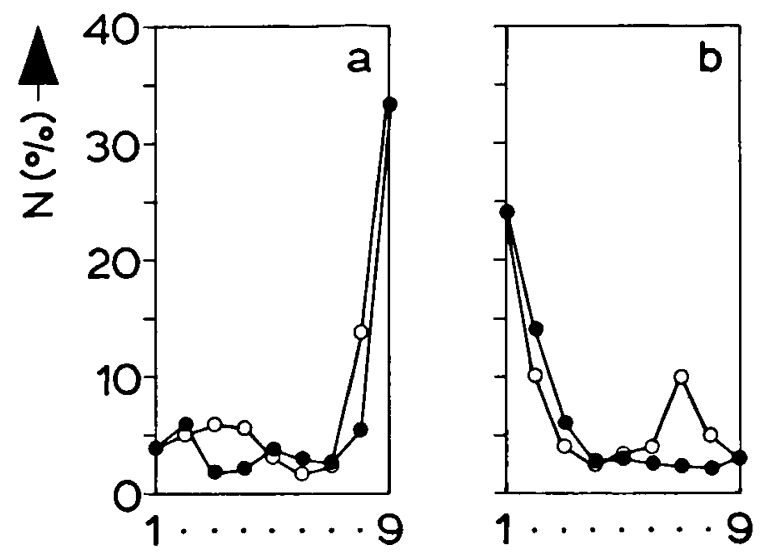

Fig. 6. As fig. 4. a, Bright side in sector 9, situation after 20 hours; $b$, gradient filter was rotated over $180^{\circ}$, bright side in sector 1 , situation after 11 hours. Whatever the direction of the gradient, the larvae move to its bright side.
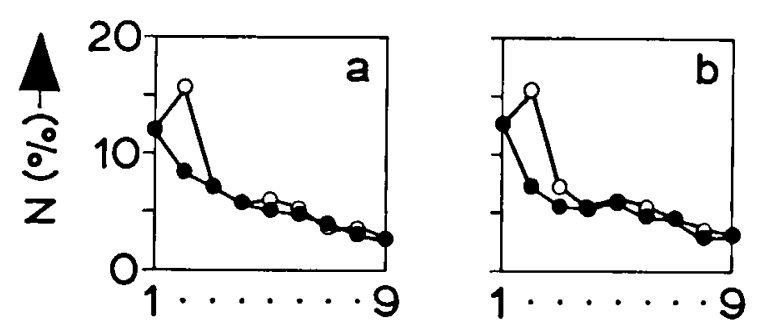

Fig. 7. Light gradient experiment with planulae of $E$. singularis in full sunshine. a, After 2.5 hours; b, after 5.5 hours, water temperature $>30^{\circ} \mathrm{C}$, all the larvae are dead. The brightest side of the gradient filter is not pointing directly at the sun. Left sector 2 of the larvodrome is therefore the brightest one. The larvae move again to this sector, even in full sunshine.

the dark, the larvae were crowding in the left half of the basin, with preference for sectors 4 and 5 (fig. 8c). This unexpected tendency increased dramatically during the following 4.5 hours of the experiment (fig. 8d). At first some contamination of the basin was suspected to have caused the observed behaviour. It was only after staying in the dark for several minutes myself that an explanation was found. Some light was seeping through small holes and fissures in the aluminium foil covering the windows of the room. In this way one of the walls was weakly illuminated, and the preferred sectors 4 and 5 were closest to this wall. Although the incoming light was quite weak during the night (with the moon in the last quarter) and at dawn, after some minutes of accomodation I could vaguely discern the objects in the room. Apparently, this light was strong enough a stimulus for the larvae to react. After sunrise, the light was stronger of course. This sensitivity for very weak irradiance, which may be widespread among invertebrate larvae, helps to explain how larvae with a built-in light response react during the night, a question raised by Thorson (1964). The answer simply seems to be that they react in the same way upon a weak stimulus (moonlight, starlight) as they do upon a strong one (sunlight), although the reaction is much slower. This also explains why the larvae in the 36 hour "dark" experiment (fig. 5) did not redistribute themselves over the basin: the gradiant perceived was sufficiently sharp to keep them in the brightest sector.

\section{c. Tracking of la rva e}

Although in all the previous experiments the larvae accumulated in areas with strongest irradiance, it is not yet clear by what mechanism these were reached. Two broad types of behaviour exist by which animals aggregate in a preferred area: taxes and kineses (Fraenkel \& Gunn, 1961). Phototaxis is a directional reaction, resulting from the decision to move towards (or away from) a lightsource (Fraenkel \& Gunn, 1961; Siebeck, 1976), and this mechanism was ruled out, since the experimental set-up used lacked any directional information about where greater or lesser light intensities were to be found. The possible explanation could therefore only be given by photokinesis, i.e. the response to light by which an animal reaches, along a nondirectional path, some region of particular stimulative intensity. Ullyott (1936b) who used the term photophobotaxis for this phenomenon, in a series of experiments with the freshwater planarian Dendrocoelum lacteum (Müller), explained how an animal that is apparently making random movements will move up (or down) a gradient as a result of a different "rate of change of direction" (r.c.d.) under the influence of increasing stimulative intensities, while in constant (or decreasing) stimulation adaptation takes place. In this way, alternative adaptation and stimulation occur when an animal is moving up or down a non-directional gradient as a result of its random movements, 

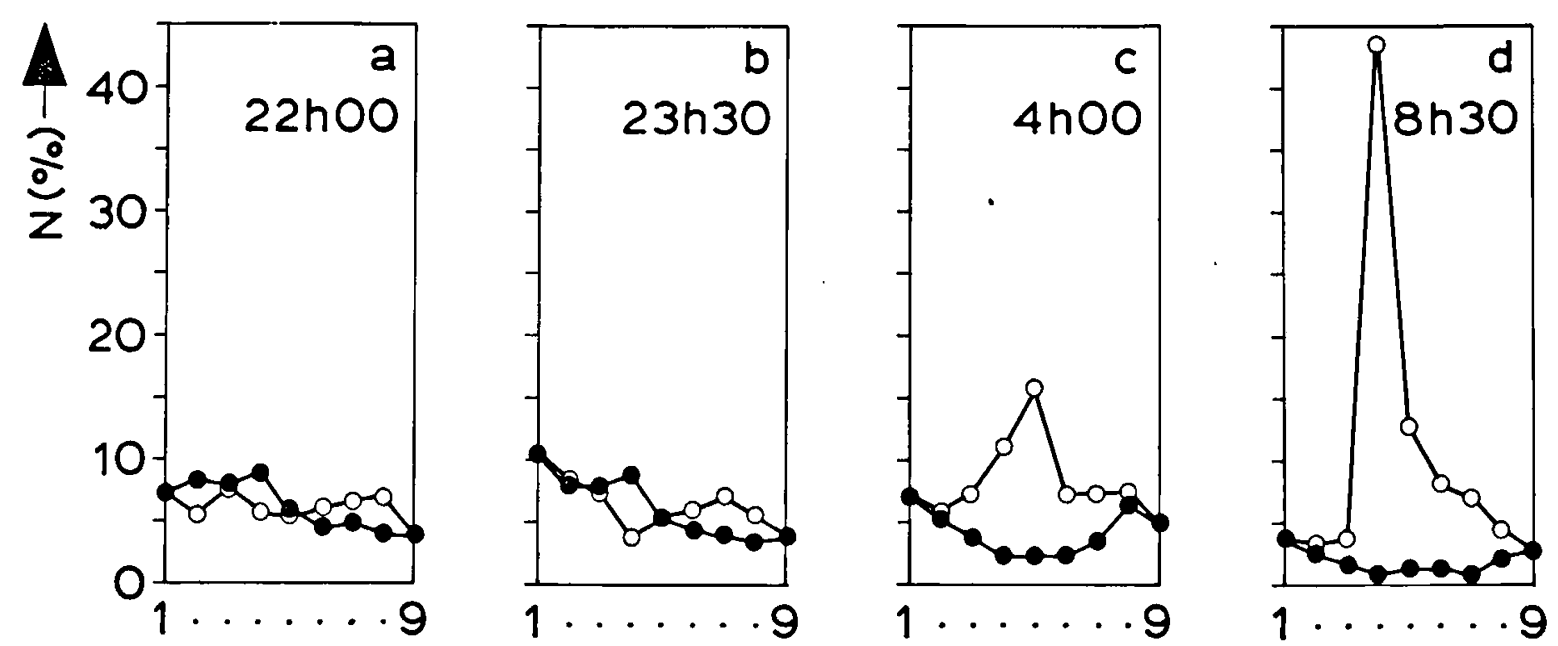

Fig. 8. Experiment with the larvodrome in the dark. a, Random distribution of the larvae of E. singularis after 2.5 hours; b, ditto, after 4 hours; c, after 8.5 hours larvae start accumulating in the left gradient, due to a very weak light in the room (see text); d, ditto, after 13 hours. Local time is indicated for each situation.

leading the animal automatically to the place of minimum stimulative intensity. This behaviour was called photoklinokinesis by Fraenkel \& Gunn (1961). Recently (Stasko \& Sullivan, 1971), this interpretation has been proved to be rather questionable, since these authors found light-dependent behaviour of planarians to be the result of responses to scattered lateral light, and therefore to be of a phototactic and not of a photokinetic nature.

Other explanations have been given, such as a decrease in activity (speed) in areas with optimum stimulation intensity, a phenomenon called orthokinesis by Fraenkel \& Gunn (1961). In this case, randomly moving animals will wander accidentally into a "preferred" area, and remain there longer on the average than in other areas, which eventually leads to an accumulation of animals in the preferred area (Siebeck, 1976). Another mechanism is a "shock reaction" at the boundary of two areas with different. stimulation intensities. Randomly moving animals have been described to move from light into dark without any reaction, but to show a shock reaction when crossing the boundary the other way round. As a result, the animals were trapped in the dark area. Ullyott (1936a) was very sceptical about this mechanism, which he ascribed to phototactic responses to directional stimuli of so low intensities that they had been overlooked by the previous investigators. It is ironical that his own experiments (Ullyott, 1936b) are claimed to be unreliable on the same grounds (Stasko \& Sullivan ,1971).

When larvae of $E$. singularis were released in the square glass tray illuminated by the four quadrants as described before, they were tracked for periods ranging from one to forty minutes. The results of some of these experiments are shown in figs. 9-11. Although the place of each larva was recorded every 5 seconds, in the figures 10second intervals are given. For each larva the beginning (b) of the experiment started at a random point of its course. The experiment stopped whenever a larva left the projected quadrants, or at a moment chosen by the investigator. The end (e) of each track is also indicated. Although differences in crawling speed occurred from one planula to the other (see also Weinberg \& Weinberg, 1979: fig. 5), the speed of each larva remained rather constant during the experiments. The highest velocity recorded in planulae of $E$. singularis. $18 \mathrm{~cm} \mathrm{~min}^{-1}$, was reached by larva $\mathrm{A}$ (fig. 10) during the period 40-50 seconds after the beginning of its tracking. Fig. 9 shows the tracks of two larvae, both moving along a rather erratic track, leading each one to cross the lightdark boundary several times in either direction, but a shock reaction was never observed. The same can be said for fig. 10, where the paths of the 


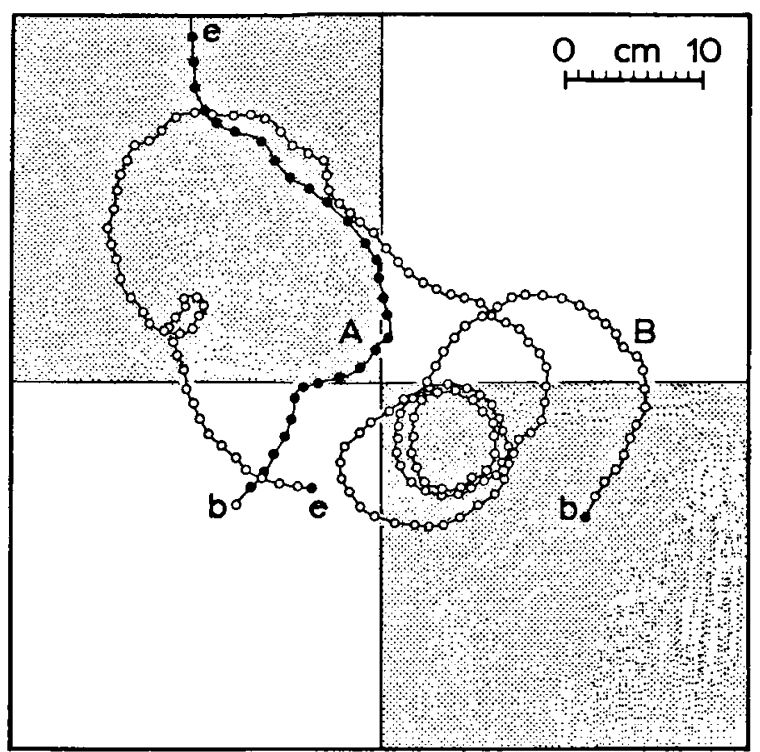

Fig. 9. Tracking of larvae of E. singularis crawling in a glass tray upon which two bright and two dark quadrants are projected. Distance between two symbols corresponds to 10 seconds. $b=$ beginning, $e=$ end of track. Larva $A$ is faster than larva $B$. Both follow an erratic course and show no shock reaction at the light-dark boundaries.

observed larvae are less erratic, but spiralling outwards, thus covering a given area efficiently.

Another characteristic of the larvae of $E$. singularis is their so-called "exploratory behaviour" in which they will remain at a given spot, thereby rotating rapidly, mostly in a counterclockwise direction (Weinberg \& Weinberg, 1979). The question remained whether the larvae would do so preferably in the illuminated quadrants. Fig. 11 shows the tracks of four different larvae. Arrows indicate spots where exploratory behaviour occurred, together with the number of seconds that this behaviour was observed. The larvae stop in the light and in the dark as well, yielding no explanation for the observed crowding in the light.

According to my observations the larvae show no shock reactions at light-dark boundaries, and they show no differences in speed nor do they stop preferentially in either light or dark quadrants. The possibility remained that their rate of change of direction (r.c.d.) would increase in the dark, which according to Ullyott (1936b) would ultimately drive them into the light. Analysis of the tracks of 21 larvae yielded the following average r.c.d.-values (in angular degrees per minute):



Fig. 11. As fig. 9. Arrows with numbers indicate where larvae stopped for "exploratory behaviour", and the number of seconds that this behaviour was observed. Larvae stop in light as well as in dark auadrants.

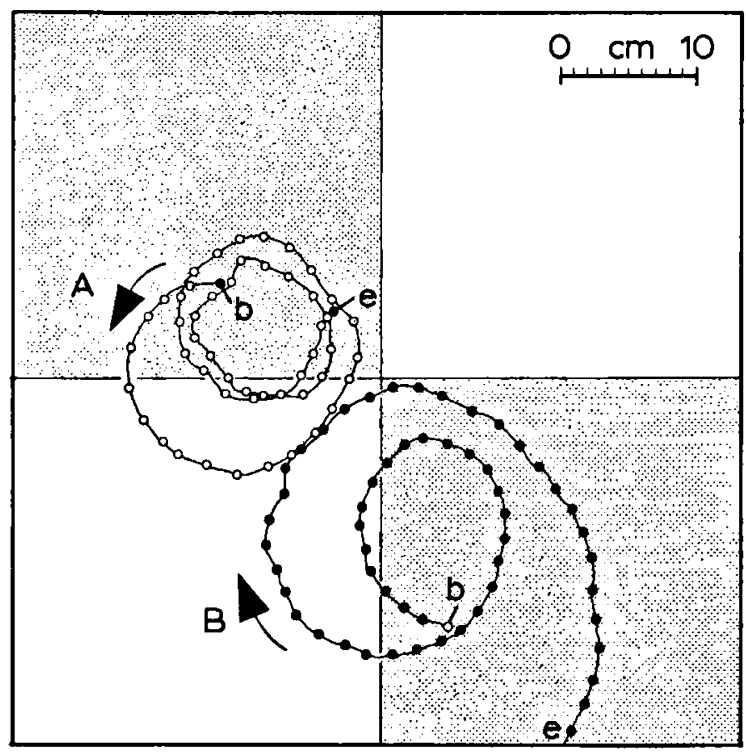

Fig. 10. As fig. 9. Both larvae follow courses spiralling outwards, larva A moving in a counterclockwise, larva B in a clockwise direction.

in the dark: $149^{\circ} \min ^{-1}$ (standard deviation $133^{\circ} \mathrm{min}^{-1}$ )

in the light: $129^{\circ} \mathrm{min}^{-1}$ (standard deviation $109^{\circ} \mathrm{min}^{-1}$ ). 
60 .
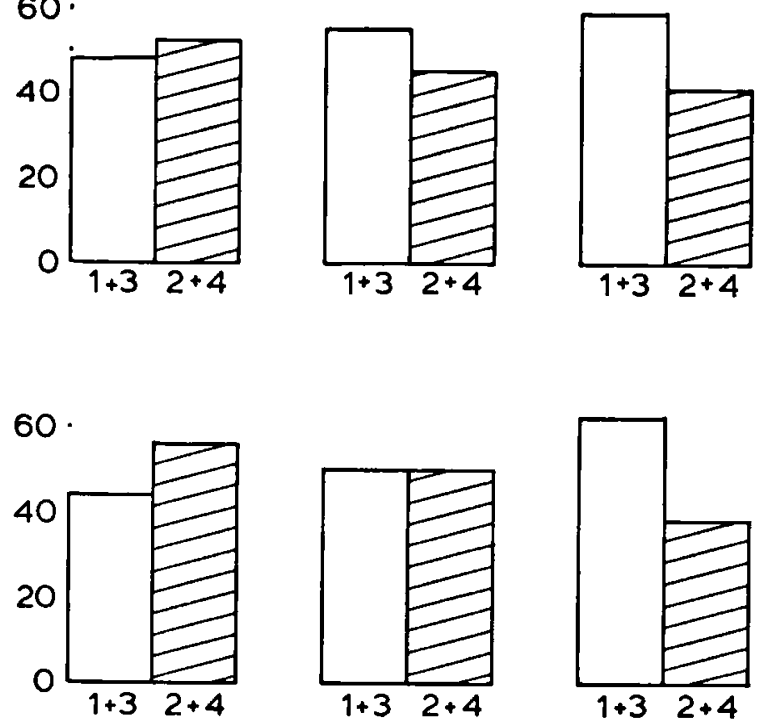
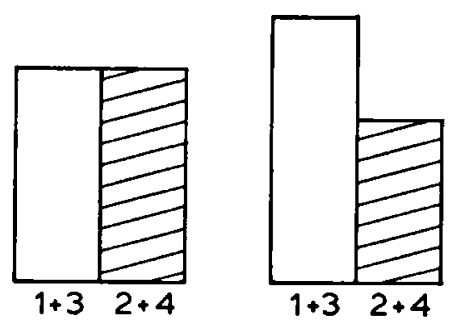

Fig. 12. Light-dark experiments with planulae of C. rubrum. Quadrants $1+3$ are illuminated, quadrants $2+4$ in the dark. Larvae show no systematic preference. ( $\mathrm{N}$ in \%).

Although this indicates that the r.c.d.-mechanism might be involved here, the null hypothesis that the values found belong to the same normally distributed population can only be rejected at the very poor level of $17.7 \%(U=1.35)$.

\section{Corallium rubrum}

a. Light-dark experiments

Light-dark experiments carried out in the circular glass dish with planulae of $C$. rubrum between 2 September and 9 September 1978 never led to an outspoken preference for either light or dark

quadrants. Fig. 12 shows the obtained results. In three cases more larvae had gathered in the light, in two cases more were found in the dark and in one case equal amounts were found. A MannWhitney $U$-test was carried out, and the $U$-value found $(U=14)$ far too high for rejection of $H_{o}$ (equal amounts of larvae in dark and illuminated quadrants). On the other hand, the planulae showed negative geotropism and gregariousness. In the rearing aquaria as well as in the experimental set-up, the larvae were always found in clusters at the water surface, never on the bottom, and seldom isolated.

\section{b. Light gradient experiments}

These experiments led to the same observations as those in the preceding paragraph. Although actively moving (see the differences between fig. 13a and $b$ ), the larvae never showed a preference for any light condition. Distribution of the larvae is not very even, however, due to gregariousness. Aggregations appear in fig. 13.

\section{CONCLUSIONS AND DISCUSSION}

\section{Eunicella singularis}

Larvae of E. singularis show a photopositive behaviour. Although the outset of the experiments was to test the behaviour of the planulae in nondirectional light gradients, the amount of light reflected by the vertical walls of the different experimental set-ups used (especially the two nontransparent ring-shaped basins) may have played
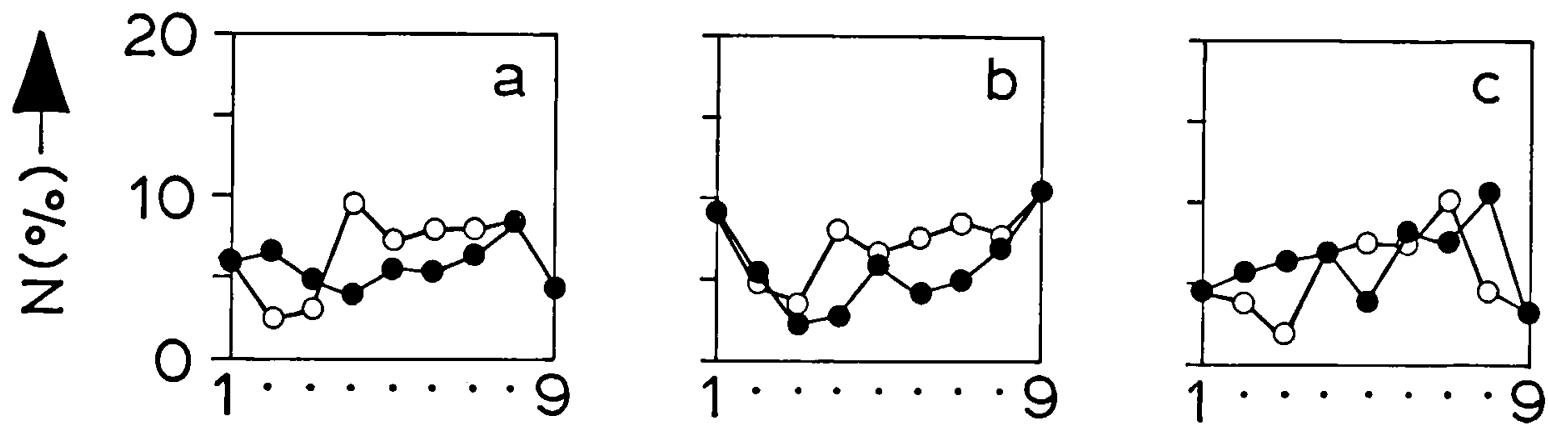

Fig. 13. Light gradient experiments with larvae of $C$. rubrum. Number of larvae (N in \%) for each sector of the larvodrome. Open symbols = left gradient, closed symbols = right gradient. Bright side of gradient in sector 1. a, b, Same experiment, $a$, after 2.5 hours, b, after 7 hours. The larvae move, but not towards any particular irradiance value. $c$, Ditto, another experiment, after 7 hours and 15 minutes. 
an important role, especially since this proved to be the disturbing factor even in the experiments of Stasko \& Sullivan (1971), who did everything to avoid scattered light in their experimental regime. It is possible, therefore, that the planulae reacted to directional stimuli, in which case their erratic behaviour corresponds to photoklinotaxis rather than photoklinokinesis. It is not clear in what way the larvae move to the bright side of a light gradient, but the possibility remains that the r.c.d.-mechanism (Ullyott, 1936b) is involved. It is not known in what way octocoral planulae perceive (differences in) light, but a "dermal light sense" is widespread among invertebrates (Millott, 1957; Steven, 1963). It is possible that the cilia, or the ciliary-microvillous complexes of the ectoderm (fig. 14) play a role as primitive photoreceptors (see Vanfleteren \& Coomans, 1976). Another possibility is that the pink yolk material contains some photosensitive pigment, if so probably carotenoids (Millott, 1957) or that the symbiotic zooxanthellae play a role, thus causing indirect photosensitivity.



Fig. 14. Ciliary-microvillous complex of the ectoderm of a planula larva of $E$. singularis. Cross-section of the basal part of a cilium (ci) surrounded by a corona of microvilli ( $\mathrm{mv}$ ). Tubules (tu) are arranged in the $9+2$ pattern. In addition to their locomotory function, these complexes may play a role in photosensitivity. Magnification: $55000 \times$. (Electron micrograph by W. Schäfer).
The consequence of this photopositive behaviour would be to find dense surface populations, decreasing where irradiance conditions decrease. This is not the case. Weinberg $(1978,1979)$ did not encounter the species in stations with extremely high irradiance, and greatest population densities occurred in stations with an irradiance of 1000$2000 \mathrm{cal} \mathrm{cm}^{-2}$ year $^{-1}$, which corresponds to about $5 \%$ of subsurface irradiance. In the surface layers water conditions are probably too turbulent for the planulae of $E$. singularis to settle. For this reason, even if larvae do crawl to the surface, they will be swept off the substratum. Hence, settlement will only take place in deeper, calmer, layers. Here, the larvae will always seek places with maximum irradiance, which will lead to a preference for horizontal surfaces over other slope types. Before selecting a suitable place for settlement, they are able to explore the bottom over distances of at least 2-40 metres (Weinberg \& Weinberg, 1979). This indeed seems to be the case, as reflected by underwater observations on distribution of adult colonies (see Weinberg, 1978: fig. 5).

For a possible usefulness of this behaviour two tentative explanations may be given. The first is that (most of) the colonies of E. singularis contain zooxanthellae ( $E$. singularis singularis (cf. Théodor, 1969)). To perform optimally, the zooxanthellae need places with high irradiance values. Kawaguti (1944) states that all (hexacoral) larvae with zooxanthellae are photopositive. Although Thorson (1964) gives some exceptions to this rule, it might be worthwhile in this respect to investigate upon the behaviour of larvae of $E$. singularis apbyta, the form lacking zooxanthellae (Théodor, 1969). The second fact of importance may be that many larvae of benthic invertebrates are photophobic at the moment of settlement. The planulae of $E$. singularis, who remain photophilous till metamorphosis, therefore define a niche where spatial competition will be less than in shaded places. This is also confirmed by underwater observations. E. singularis is a dominant species in its habitat (see Weinberg \& Weinberg, 1979: plate 1A). As a whole, it may be concluded that the photopositive behaviour of planulae of $E$. singularis contributes to the distribution pattern of the species as found in nature. 


\section{Corallium rubrum}

Planulae of $C$. rubrum are indifferent to irradiance and negatively geotactic. As a result, colonies of this species may be expected to occur near the surface. Again, this is not the case. On the contrary, C. rubrum is found in deeper places. In Banyuls, it was never found at less than $20 \mathrm{~m}$, and the species still occurs at $280 \mathrm{~m}$ depth (Reyss, 1971). Moreover, the species is found in dark places (<130 cal cm-2year ${ }^{-1}$; Weinberg, 1979), with maximum population densities in dark caves and overhanging surfaces in shallow water (Laborel \& Vacelet, 1961; Weinberg, 1975, 1978, 1979). At $200 \mathrm{~m}$ depth it is found on vertical walls (Carpine \& Grasshoff, 1975) and at $280 \mathrm{~m}$ even on horizontal ledges (Reyss, 1971). Thus, with increasing depth (decreasing irradiance) the species changes from cryptophilic to acrophilic habitats.

These ecological facts cannot be explained by the larval behaviour. If cave-dwelling colonies of C. rubrum release their planulae, these will gather at the ceiling of the cave as a result of their geonegative behaviour and be trapped there till settlement. Although the dense populations occurring in underwater caves can be explained in this way, this impedes dispersion of the species, as it tends to keep the populations apart, each in its own cave. There is no evidence that this is the case, and not all populations are confined to caves (see above). It is probable therefore that larval dispersion takes place as in most other species. Planulae are carried with currents to different habitats. On the grounds of the observations described in this article, the larvae may not be expected to crawl away from the light. Therefore, they will probably metamorphose under very different irradiance conditions. The fact that adult colonies are only encountered in dark places may therefore be explained by the tolerance of the colonies rather than the preferences of the planulae. Experiments involving adult animals are needed in order to elucidate these phenomena.

\section{ACKNOWLEDGEMENTS}

I wish to acknowledge Dr. Jacques Soyer, Director of the Laboratoire Arago in Banyuls-sur-Mer for the use of his laboratory facilities during my visits. I thank Dr. Roger Prodon (Laboratoire Arago) for his enthousiastic and helpful suggestions during the experimental work. Miss Charlotte
Van Duijl carried out some preliminary experiments. I am very grateful to Mr. Herman Mittelberg for his skilful participation in the construction of the experimental set-ups, and to Mrs. Anne Pollet and Miss Karin Sauer of the "Mas d'Avall" pottery (Cosprons), who generously made the stoneware basin according to my specifications. Dr. Wolfgang Schäfer (Zoologisches Institut, Heidelberg University) is acknowledged for the picture appearing in fig. 14. Prof. Dr. Jan H. Stock and Prof. Dr. C. den Hartog are acknowledged for critically reading the manuscript. Dr. Ian R. Ball kindly polished my English text.

This research was carried out under grant 87-117 from the Netherlands Organization for the Advancement of Pure Research (Z.W.O.).

\section{REFERENCES}

ATODA, K., 1947. The larva and postlarval development of some reef-building corals, 1. Pocillopora damicornis cespitosa (Dana). Sci. Rep. Tohoku Univ., (4) (Biol.) 18 (1): $24-47$.

-, 1951a. The larva and postlarval development of the reef-building corals, 4. Galaxea aspera Quelch. J. Morph., 89: $17-30$.

— $1951 \mathrm{~b}$. The larva and postlarval development of some reef-building corals, 5. Seriatopora hystrix Dana. Sci. Rep. Tohoku Univ., (4) (Biol.) 19 (1): 33-39.

BAYNE, B. L., 1969. The gregarious behaviour of the larvae of Ostrea edulis L. at settlement. J. mar. biol. Ass. U.K., 49: $327-356$.

Carpine, C. \& M. Grasshoff ,1975. Les gorgonaires de la Méditerranée. Bull. Inst. océanogr. Monaco, 71 (1430): $1 \cdot 140$.

CARThy, J. D., 1958. An introduction to the behaviour of invertebrates: i-xi, 1-380 (George Allen \& Unwin Ltd., London).

Crisp, D. J. \& D. A. Rrrz, 1973. Responses of cirripede larvae to light, 1. Experiments with white light. Mar. Biol., 23: 327-335.

CRISP, D. J. \& J. S. RYLAND, 1960. Influence of filming and of surface texture on the settlement of marine organisms. Nature, 185 (4706): 119.

Elliotr, J. M., 1977. Some methods for the statistical analysis of samples of benthic invertebrates. Freshw. biol. Assoc., sci. Publ., 25: 1.156.

Ercegovic, A., 1957. Principes et essai d'un classement des étages benthiques. Rec. Trav. Stat. mar. Endoume, 22 (13): 17-21.

Fraenkel, G. S. \& G. L. GunN, 1961. The orientation of animals: i-x, 1-376 (Dover Publications, New York).

GohaR, H. A. F., 1940. The development of some Xeniidae (Alcyonaria) (with some ecological aspects). Publ. mar. biol. Stat. Ghardaqa (Red Sea), 3: 27-79.

KaWAGUTI, S., 1941. On the physiology of reef corals, 5. Tropisms of coral planulae, considered as a factor of distribution on the reefs. Palao trop. biol. Stud., 2: 319-328.

$\ldots, 1944$. Zooxanthellae as a factor of positive phototropism in those animals containing them. Palao trop. biol. Stud., 2: $681-682$.

KNIGHT-JoNES, E. W., 1951. Gregariousness and some other aspects of the settling behaviour of Spirorbis. J. mar. biol. Ass. U.K., 30: 201-222. 
KoCH, G. voN, 1887. Die Gorgoniden des Golfes von Neapel und der angrenzenden Meeresabschnitte. Erster Theil einer Monographie der Anthozoa Alcyonaria. Fauna Flora Golf. Neapel, 15: i-x, 1-99, pls. 1-10.

LABOREL, J. \& J. VACELET, 1961. Répartition bionomique du Corallium rubrum Lmck dans les grottes et falaises sousmarines. Rapp. Proc. Réun. C.I.E.S.S.M., 16 (2): 465-469.

LACAZE-DUTHIERS, H. DE, 1864. Histoire naturelle du corail. Organisation-reproduction-pèche en Algérie - Industrie et Commerce: i-xxv, 1-371, pls. I-XX (J. B. Baillière \& Fils, Paris).

LEwIS, J. B., 1974. The settlement behaviour of planulae larvae of the hermatypic coral Favia fragum (Esper). J. exp. mar. Biol. Ecol., 15: 165-172.

LOEB, J. \& H. WASTENEYS, 1917. A reexamination of the applicability of the Bunsen-Roscoe law to the phenomena of animal heliotropism. J. exp. Zool., 22 (1): 187-192.

Meadows, P. S. \& J. I. Campbell, 1972. Habitat selection by aquatic invertebrates. Adv. mar. Biol., 10: 271-382.

MIllotT, N., 1957. Animal photosensitivity, with special reference to eyeless forms. Endeavour, 16 (61): 19-28.

PRODON, R., 1976. Le substrat, facteur écologique et éthologique de la vie aquatique: observations et expériences sur les larves de Micropterna testacea et Cordulogaster annulatus. Thesis, Univ. Claude Bernard, Lyon: 1-221.

ReYss, D., 1971. Les canyons sous-marins de la mer Catalane, le Rech du Cap et le Rech Lacaze-Duthiers, 3. Les peuplements de macrofaune benthique. Vie Milieu, 22 (3B): 529-613.

Siebeck, O., 1976. Photorezeptoren und Photorezeption (Sinnesphysiologie, Teil E). Handb. Biol., 5 (22-31): 1-218.

Stasko, A. B. \& C. M. Sullivan, 1971. Responses of planarians to light: an examination of klino-kinesis. Anim. Behav., 4 (2): 1-124.

Steven, D. M., 1963. The dermal light sense. Biol. Rev., 38: 204-240.

ThÉODOR, J., 1967. Contribution à l'étude des gorgones (7): écologie et comportement de la planula. Vie Milieu, 18 (2A): 291-301.

—_ 1969. Contribution à l'étude des gorgones (8): Eunicella stricta aphyta sous-espèce nouvelle sans zooxanthelles, proche d'une espèce normalement infestée par ces algues. Vie Milieu, 20 (3A): 635-638.

Thorson, G., 1950. Reproductive and larval ecology of marine bottom invertebrates. Biol. Rev. Cambridge phil. Soc., 25 (1): 1-45.
- 1964 . Light as an ecological factor on the dispersal and settlement of larvae of marine bottom invertebrates. Ophelia, 1: 167-208.

UllyotT, P., 1936a. The behaviour of Dendrocoelum lacteum, 1. Responses at light-and-dark boundaries. J. exp. Biol., 13 (3): 253-264.

1936b. The behaviour of Dendrocoelum lacteum, 2. Responses in non-directional gradients. J. exp. Biol., 13 (3): 265-278.

Vanfleteren, J. R. \& A. Coomans, 1976. Photoreceptor evolution and phylogeny. Z. zool. Syst. Evolut.-Forsch., 14: $157-169$.

VIGHI, M., 1970. Ricerche sul ciclo riproduttivo del corallo rosso (Corallium rubrum (L.)) del promontorio di Portofino. Atti Accad. naz. Lincei, Memorie, (8) 10 (IIIa, 1): 1-26.

WALTON SMITh, F. G., 1948. Surface illumination and barnacle attachment. Biol. Bull., 94 (1): 33-39.

WEDLER, E., 1975. Ökologische Untersuchungen an Hydroiden des Felslitorals von Santa Marta (Kolumbien). Helgoländ. wiss. Meeresunters., 27: 324-363.

WeINBERG, S., 1975. Ecologie des Octocoralliaires communs du substrat dur dans la région de Banyuls-sur-Mer. Essai d'une méthode. Bijdr. Dierk., 45 (1): 50-70.

- 1978. Mediterranean octocorallian communities and the abiotic environment. Mar. Biol., 49: 41-57.

- 1979. Autecology of shallow-water Octocorallia from Mediterranean substrata, 1 . The Banyuls area. Bijdr. Dierk., 49 (1): 1-15.

Weinberg, S. \& A. M. Cortel-Breeman, 1978. The estimation of the yearly cycle of submarine irradiance for ecological purposes. A methodological example based on data from Banyuls-sur-Mer (France). Bijdr. Dierk., 48 (1): 35-44.

WeINBERG, S. \& F. WeInBERG, 1979. The life cycle of a gorgonian: Eunicella singularis (Esper, 1791). Bijdr. Dierk., 49 (1): 1-15.

Williams, G. B., 1965. Observations on the behaviour of the planulae larvae of Clava squamata. J. mar. biol. Ass. U.K., 45: 257-273.

- 1976. Aggregation during settlement as a factor in the establishment of coelenterate colonies. Ophelia, 15 (1): 57-64.

WILsON, D. P., 1968. The settlement behaviour of the larvae of Sabellaria alveolata (L.). J. mar. biol. Ass. U.K., 48: 387-435. 